1 Universidade Federal de Minas Gerais (UFMG),

Faculdade de Medicina (FM), Programa de PósGraduação de Promoção de Saúde e Prevenção da Violência - Belo Horizonte (MG), Brasil.

Orcid: https://orcid. org/0000-0001-57624269

dorianaozolio@gmail.com

2 Universidade Federal de Minas Gerais (UFMG),

Faculdade de Medicina (FM), Programa de PósGraduação de Promoção de Saúde e Prevenção da Violência - Belo Horizonte (MG), Brasil.

Orcid: https://orcid org/0000-0002-3179-

7177

re.psi@globo.com

3 Universidade Federal de Minas Gerais (UFMG) Faculdade de Medicina (FM), Programa de PósGraduação de Promoção de Saúde e Prevenção da Violência - Belo Horizonte (MG), Brasil.

Orcid: https://orcid. org/0000-0003-02821913

tatamunick@hotmail.com

4 Universidade Federal de Minas Gerais (UFMG), Faculdade de Medicina (FM), Programa de PósGraduação de Promoção de Saúde e Prevenção da Violência - Belo Horizonte (MG), Brasil.

Orcid: https://orcid. org/0000-0002-35770721

elzammelo@hotmail.com

5 Universidade Federal de Minas Gerais (UFMG), Faculdade de Medicina (FM), Programa de PósGraduação de Promoção de Saúde e Prevenção da Violência - Belo Horizonte (MG), Brasil.

Orcid: https://orcid.

org/0000-0003-1014-

7762

victormelo2401@gmail.com

\section{Violência provocada pelo parceiro íntimo entre usuárias da Atenção Primária à Saúde: prevalência e fatores associados}

\author{
Violence caused by an intimate partner in users of Primary Health \\ Care: prevalence and associated factors \\ Doriana Ozólio Alves Rosa', Renata Cristina de Souza Ramos², Talita Munick Vieira Gomes ${ }^{\mathbf{3}}$, Elza \\ Machado de Melo 4 , Victor Hugo Melo 5
}

DOI: $10.1590 / 0103-110420185405$

RESUMO A violência provocada por parceiro íntimo é reconhecida mundialmente como um problema de saúde pública. Investigaram-se a prevalência e os fatores associados a esse tipo de violência em 470 mulheres usuárias da Atenção Primária à Saúde, em um município da Região Metropolitana de Belo Horizonte, Minas Gerais. Trata-se de estudo transversal, utilizando distribuições de frequência e teste Qui-quadrado de inúmeras variáveis e regressão logística final. Os resultados apontam que a violência contra a mulher é um fenômeno de alta frequência e pode estar associado à baixa escolaridade e ao consumo de álcool. A Atenção Primária à Saúde é um dos locais mais procurados pelas mulheres em situação de violência. Assim, é fundamental que os profissionais de saúde se envolvam no combate à violência contra a mulher.

PALAVRAS-CHAVE Violência contra a mulher. Violência doméstica. Mulheres agredidas. Maustratos conjugais. Atenção Primária à Saúde.

ABSTRACT Violence caused by an intimate partner is recognized worldwide as a public health problem. It was investigated the prevalence and factors associated with this kind of violence in 470 women users of Primary Health Care, in a municipality of the Metropolitan Region of Belo Horizonte, Minas Gerais. This is a cross-sectional study, using frequency distributions and Chisquare test of several variables and final logistic regression. The results indicate that violence against women is a high frequency phenomenon and can be associated to low education and alcohol consumption. Primary Health Care is one of the most required places by women in situation of violence. Therefore, is fundamental that health professionals become involved in combating violence against women.

KEYWORDS Violence against women. Domestic violence. Battered women. Spouse abuse. Primary Health Care. 


\section{Introdução}

A Violência Provocada por Parceiro Íntimo (VPPI) é definida como o comportamento dentro de uma relação íntima que provoca danos físicos, sexuais ou psicológicos, incluindo atos de agressão física, coerção sexual, abusos psicológicos e comportamentos intimidadores. Devido à própria natureza da violência sexual e da violência praticada por parceiro íntimo, a ocorrência e os impactos causados são subestimados ${ }^{1}$.

De acordo com a Organização Mundial da Saúde (OMS), são fatores de risco para a ocorrência da VPPI: juventude; baixo nível de escolaridade; ser separada ou divorciada; ter sido exposta a maus-tratos na infância; violência entre os pais; uso nocivo do álcool; uso ilícito de drogas; e aceitação da violência².

Estudo realizado pela Organização PanAmericana da Saúde (Opas) em 12 países da América Latina e Caribe, envolvendo 228.143 mulheres, mostrou que a prevalência da VPPI é alta, variando com relação às dimensões física, psicológica e sexual. Entre as mulheres entrevistadas, 13,4 a $52,3 \%$ relataram a ocorrência de violência física provocada pelo parceiro, em algum momento de suas vidas ${ }^{2}$.

Por sua vez, o fenômeno da violência contra a mulher perpassa todas as classes e segmentos sociais, e é no âmbito doméstico que acontece a maior parte das situações de violência vivenciadas pelas mulheres. No Brasil, em 2011, em $70 \%$ dos registros de atendimentos realizados em mulheres vítimas da violência, o local do evento foi a própria casa da vítima ${ }^{3}$.

O serviço de Atenção Primária à Saúde (APS) é um dos locais mais procurados pelas mulheres em situação de violência. No entanto, a violência não se apresenta como uma demanda imediata ao serviço, surgindo mais como uma demanda implícita ${ }^{4}$. As mulheres que convivem com a VPPI fazem maior uso dos serviços de saúde, principalmente em associação com a gravidade e a reiteração desse tipo de violência ${ }^{5}$. Assim, a violência contra a mulher é uma realidade no cotidiano dos profissionais de saúde da atenção primária, e estes vêm subnotificando os casos de violência ${ }^{4,6}$.

Apesar de a notificação da violência contra a mulher ser obrigatória em todo o território nacional, devendo ser realizada pelo profissional de saúde que atendeu a vítima, ela ainda não está devidamente implementada ${ }^{7}$. O reconhecimento da violência de gênero como um problema de saúde pública é recente, sendo possível que os profissionais de saúde ainda desconheçam as suas consequências para a saúde da mulher, além de não se sentirem capazes e seguros para notificar os casos de violência ${ }^{\mathbf{4}, 6}$.

O objetivo do presente estudo foi investigar a prevalência e os fatores associados à violência contra a mulher, provocada por parceiro íntimo, a partir de entrevistas de usuárias da APS em um município da Região Metropolitana de Belo Horizonte, Minas Gerais.

\section{Metodologia}

Este é um estudo transversal, de natureza quantitativa, aninhado na pesquisa 'Programa de Promoção de saúde e Prevenção da Violência na Atenção Básica', realizada no município de Ribeirão das Neves, região metropolitana de Belo Horizonte, Minas Gerais, Brasil, em julho de 2012. A pesquisa 'Programa de Promoção de Saúde e Prevenção da Violência na Atenção Básica' é coordenada pelo Núcleo de Saúde e Paz, do Departamento de Medicina Preventiva e Social da Universidade Federal de Minas Gerais, Brasil.

Foram entrevistadas mulheres residentes nesse município, recrutadas a partir das 53 Unidades Básicas de Saúde (UBS) e de 5 Unidades Básicas de Referência (UBR), locais onde ocorreram as entrevistas individuais. Foi utilizada uma tabela de números aleatórios para selecionar as usuárias, a partir de sua ordem de chegada à unidade de saúde. Foram definidos os seguintes critérios de inclusão: ter idade maior ou igual a 15 anos; ser do sexo feminino; ter tido parceria afetivo-sexual alguma vez na vida; ter sido atendida na UBS 
pelo menos uma vez antes da entrevista; e ser moradora do local há mais de um ano.

O questionário aplicado foi construído pela equipe da pesquisa 'Programa de Promoção de Saúde e Prevenção da Violência na Atenção Básica', tendo sido composto por dois núcleos: 1) O primeiro abordava as características pessoais e sociodemográficas dos indivíduos, sua ocupação/trabalho, relações pessoais e comunitárias estabelecidas, além de sua percepção de saúde e os tipos de violência sofrida; 2) Para confecção do segundo núcleo, utilizou-se parte do questionário referente ao estudo multicêntrico realizado pela OMS, intitulado 'Estudo Multipaíses Sobre a Violência Doméstica’8, e validado no Brasil9. Desse questionário, foram aplicadas às usuárias perguntas contidas em duas seções: 1) Seção 7 - 'A Entrevistada e seu companheiro'; 2) Seção 10 - 'Outras Experiências'. As perguntas referentes a essas seções abordavam o tema da violência contra a mulher, provocada pelo parceiro íntimo, nos seus aspectos físico, sexual e psicológico. O questionário foi testado previamente com membros da própria equipe de pesquisa. Aprovada sua versão final, foi realizado o treinamento para os aplicadores.

Foi definido como parceiro íntimo o companheiro ou ex-companheiro com o qual a mulher vive ou já viveu, independentemente de ser uma união formal, incluindo-se aí os parceiros atuais ou anteriores, desde que tenha havido relação sexual.

As variáveis independentes analisadas foram agrupadas em quatro blocos: características sociodemográficas (idade; estado civil; grau de instrução; chefe da família; renda familiar; número de pessoas na casa; trabalho; desemprego na família; consumo de bebida alcoólica); autopercepção da saúde (utiliza o Sistema Único de Saúde - SUS; tem algum problema de saúde; como avalia sua saúde; grau de dores no corpo; quando procurou o médico pela última vez; dor de cabeça ou enxaqueca); violências sofridas e praticadas pela mulher (sofreu alguma violência nos últimos 12 meses; tipo de violência sofrida - física, verbal, psicológica/moral, sexual -; quem agrediu; se achar violenta; agrediu alguém da família; tipo de agressão praticada - física, verbal, psicológica/moral, sexual); e violências provocadas pelo parceiro íntimo.

A Violência Física (VF), a Violência Psicológica (VP) e a Violência Sexual (VS), provocadas por parceiro íntimo, foram consideradas presentes quando a mulher respondeu sim a pelo menos uma das seguintes perguntas: Insultou-a ou fez com que se sentisse mal a respeito de si mesma? Depreciou você diante de outras pessoas? Intimidou ou fez coisas para assustá-la? Ameaçou machucá-la ou alguém de quem você gosta? Deu-lhe um tapa ou jogou algo? Empurrou-a ou deu um 'tranco'? Machucou-a com um soco ou objeto? Deu um chute, arrastou ou surrou? Estrangulou ou a queimou de propósito? Ameaçou usar ou usou arma de fogo, faca ou outro tipo de arma? Forçou-a fisicamente a ter relações sexuais? Teve relação sexual por medo? Forçou-a a ter prática sexual degradante?

Foi utilizado o software SPSS Statistic, versão 20, para armazenagem e análise quantitativa dos dados coletados. A partir da codificação dos dados obtidos dos questionários individuais, as informações foram inseridas com dupla entrada, para minimizar possíveis erros de digitação. Para análise dos dados, foram realizadas as distribuições de frequência das variáveis categóricas e testes estatísticos adequados para as comparações entre as variáveis, considerando-se $\mathrm{p}<0,05$. Para a análise multivariada, utilizou-se regressão logística ( $p<0,05)$, Intervalo de Confiança (IC) e Razão de chances (OddsRatio - OR).

Este estudo foi aprovado pelo Comitê de Ética em Pesquisa da Universidade Federal de Minas Gerais, Coep/UFMG, sob o ${ }^{\circ}$ 01140812.1.0000.5149, em 30/05/2012. Todas as participantes assinaram o termo de consentimento livre e esclarecido, após terem sido informadas a respeito da confidencialidade dos dados colhidos na pesquisa. No caso de participantes menores de 18 anos, os responsáveis também assinaram o Termo de Consentimento Livre e Esclarecido (TCLE). 


\section{Resultados}

Foram entrevistadas 470 mulheres, com idade entre 15 a 83 anos. A tabela 1 apresenta as características sociodemográficas das mulheres entrevistadas. Algumas informações relativas à distribuição de frequência das variáveis sociodemográficas e de alguns tipos de violência verificadas na pesquisa foram apresentadas em artigo publicado anteriormente ${ }^{10}$, e toda menção a elas, quando necessária, será referenciada a esse artigo. A maioria da população pesquisada ( $\mathrm{n}=305 ; 64,9 \%)$ era casada ou vivia em união estável. Com relação ao grau de instrução, 57,2\% ( $\mathrm{n}=269)$ possuíam tempo de escolaridade inferior a 8 anos. Renda familiar inferior ou igual a 3 salários mínimos foi relatada por 387 mulheres (82,3\%); e 319 (67,8\%) não possuíam emprego ou trabalho remunerado à época da entrevista10. A maior parte das mulheres entrevistadas utilizava o SUS, sendo que $80,4 \%(n=378)$ relataram última consulta médica há menos de 6 meses da data da entrevista. Percepção das entrevistadas sobre suas condições de saúde: 236 (50,2\%) relataram ter algum problema de saúde; 320 $(68,1 \%)$ afirmaram sentir dor de cabeça ou enxaqueca.

Tabela 1. Características demográficas e socioeconômicas das 470 mulheres entrevistadas em Ribeirão das Neves, Minas Gerais

\begin{tabular}{|c|c|c|}
\hline Variável & $\mathrm{N}=470$ & $\%$ \\
\hline \multicolumn{3}{|l|}{ Idade } \\
\hline$\leq 49$ anos & 334 & 71,1 \\
\hline$>49$ anos & 130 & 27,7 \\
\hline Não informado & 6 & 1,3 \\
\hline \multicolumn{3}{|l|}{ Estado Civil } \\
\hline Solteiraa & 165 & 35,1 \\
\hline Casadab & 305 & 64,9 \\
\hline \multicolumn{3}{|l|}{ Grau de Instrução } \\
\hline$<8$ anos de escolaridade & 269 & 57,2 \\
\hline$>8$ anos de escolaridade & 192 & 40,9 \\
\hline Não informado & 9 & 1,9 \\
\hline \multicolumn{3}{|l|}{ Chefe da Família } \\
\hline Parceiro/Marido & 251 & 53,4 \\
\hline Mulher & 106 & 22,6 \\
\hline Outros Familiares & 93 & 19,8 \\
\hline \multicolumn{3}{|l|}{ Renda Familiar } \\
\hline$\leq 3$ salários mínimos & 387 & 82,3 \\
\hline >3 salários mínimos & 55 & 11,7 \\
\hline Não informado & 28 & 6,0 \\
\hline \multicolumn{3}{|c|}{ Número de Pessoas que moram na casa } \\
\hline$\leq 4$ pessoas & 312 & 66,4 \\
\hline$>4$ pessoas & 158 & 33,6 \\
\hline \multicolumn{3}{|c|}{ Consome bebida alcoólica atualmente } \\
\hline $\operatorname{Sim}$ & 62 & 13,2 \\
\hline Não & 408 & 86,8 \\
\hline
\end{tabular}


Tabela 1. (cont.)

\begin{tabular}{|c|c|c|}
\hline \multicolumn{3}{|c|}{ Tem algum problema de saúde } \\
\hline $\operatorname{Sim}$ & 236 & 50,2 \\
\hline Não & 233 & 49,8 \\
\hline Não informado & 1 & 0,2 \\
\hline \multicolumn{3}{|c|}{ Sente dor de cabeça ou enxaqueca } \\
\hline Sim & 320 & 68,1 \\
\hline Não & 150 & 31,9 \\
\hline \multicolumn{3}{|l|}{ Se acha violenta } \\
\hline $\operatorname{Sim}$ & 118 & 25,1 \\
\hline Não & 352 & 74,9 \\
\hline \multicolumn{3}{|c|}{ Trabalha atualmente } \\
\hline $\operatorname{Sim}$ & 150 & 31,9 \\
\hline Não & 319 & 67,8 \\
\hline Não informado & 1 & 0,2 \\
\hline \multicolumn{3}{|c|}{ Desemprego na família } \\
\hline $\operatorname{Sim}$ & 199 & 42,3 \\
\hline Não & 268 & 57,0 \\
\hline Não informado & 3 & 0,6 \\
\hline \multicolumn{3}{|c|}{ Quando procurou médico } \\
\hline$<6$ meses & 378 & 80,6 \\
\hline$>6$ meses & 91 & 19,4 \\
\hline Não informado & 1 & 0,2 \\
\hline
\end{tabular}

a Solteira: mulher solteira, divorciada ou viúva.

bCasada: mulher casada ou com união estável.

A tabela 2 mostra os tipos de violência sofrida pelas mulheres, ocorridos nos últimos 12 meses. Merece destaque a violência verbal ( $n=128 ; 27,3 \%$ ), seguida da violência psicológica ou moral $(\mathrm{n}=107 ; 22,7 \%)^{\mathbf{1 0}}$. Além do parceiro íntimo, apareceram outros agressores (vizinhos, familiares, amigos e desconhecidos), que foram os responsáveis por agredir psicologicamente e/ou fisicamente $28,5 \%$ e $6,4 \%$ das mulheres entrevistadas, respectivamente. O parceiro íntimo aparece como um dos agressores em todas as ocorrências de violência relatadas. Destaca-se a ocorrência de violência psicológica ( $15,5 \%)$ e física (5,7\%) contra essas mulheres, provocada por familiares, o que se configura como violência doméstica. A mulher também aparece como agressora, cometendo agressões verbais (33,6\%), físicas (16,6 \%) e psicológicas ou morais (8,3\%). A aceitação de que eram violentas foi relatada por $25,1 \%$ das mulheres entrevistadas (informações não compiladas na tabela 2). 
Tabela 2. Tipos de violências sofridas, nos últimos 12 meses, pelas 470 mulheres entrevistadas, em Ribeirão das Neves, MG, em 2012

\begin{tabular}{|c|c|c|}
\hline Tipo de violência & $\mathrm{N}=470$ & $\%$ \\
\hline \multicolumn{3}{|l|}{ Física } \\
\hline $\operatorname{Sim}$ & 36 & 7,7 \\
\hline Não & 430 & 91,4 \\
\hline Não informado & 4 & 0,8 \\
\hline \multicolumn{3}{|c|}{ Quem agrediu fisicamente } \\
\hline Parceiro íntimoa & 14 & 2,9 \\
\hline Outros $^{b}$ & 30 & 6,4 \\
\hline Não sofreu agressão & 426 & 90,6 \\
\hline \multicolumn{3}{|l|}{ Verbal } \\
\hline Sim & 128 & 27,3 \\
\hline Não & 339 & 72,1 \\
\hline Não informado & 3 & 0,6 \\
\hline \multicolumn{3}{|l|}{ Psicológica ou moral } \\
\hline Sim & 107 & 22,7 \\
\hline Não & 358 & 76,1 \\
\hline Não informado & 5 & 1,0 \\
\hline \multicolumn{3}{|c|}{ Quem agrediu verbal, moral ou psicologicamente } \\
\hline Parceiro íntimoa & 33 & 7,02 \\
\hline Outros ${ }^{b}$ & 134 & 28,5 \\
\hline Não sofreu agressão & 303 & 64,4 \\
\hline \multicolumn{3}{|l|}{ Sexual } \\
\hline $\operatorname{Sim}$ & 13 & 2,76 \\
\hline Não & 455 & 96,8 \\
\hline Não informado & 4 & 0,8 \\
\hline \multicolumn{3}{|c|}{ Quem agrediu sexualmente } \\
\hline Parceiro íntimoa & 5 & 1,0 \\
\hline Outros $^{b}$ & 8 & 1,7 \\
\hline Não sofreu agressão & 455 & 96,8 \\
\hline
\end{tabular}

A magnitude da VPPI e a distribuição dos vários tipos de violência são apresentadas na tabela 3. Percebe-se que a violência psicológica é o evento com maior ocorrência. Por outro lado, chama atenção a alta frequência de violência física moderada (24,9\%) ou grave $(18,5 \%)$ perpetrada pelo parceiro íntimo. Violência física ocorreu alguma vez na vida de $26,0 \%$ das entrevistadas, e a psicológica foi relatada por $42,8 \%$ delas. 
Tabela 3. Violências contra as mulheres praticadas pelo parceiro íntimo, ou ex-parceiro, relatadas pelas 470 mulheres entrevistadas

\begin{tabular}{|c|c|c|}
\hline Tipo de violência & $\mathrm{N}=470$ & $\%$ \\
\hline \multicolumn{3}{|l|}{ Psicológica } \\
\hline \multicolumn{3}{|c|}{ Insultou-a ou fez com se sentisse mal a respeito de si mesma? } \\
\hline $\operatorname{Sim}$ & 201 & 42,8 \\
\hline \multicolumn{3}{|c|}{ Depreciou você diante de outras pessoas? } \\
\hline Sim & 136 & 28,9 \\
\hline \multicolumn{3}{|c|}{ Intimidou ou fez coisas para assustá-la? } \\
\hline $\operatorname{Sim}$ & 145 & 30,9 \\
\hline \multicolumn{3}{|c|}{ Ameaçou machucá-la ou alguém de quem você gosta? } \\
\hline $\operatorname{Sim}$ & 111 & 23,6 \\
\hline \multicolumn{3}{|l|}{ Física } \\
\hline \multicolumn{3}{|l|}{ Moderada ${ }^{a}$} \\
\hline \multicolumn{3}{|c|}{ Marido/companheiro deu um tapa ou jogou algo? } \\
\hline $\operatorname{sim}$ & 117 & 24,9 \\
\hline \multicolumn{3}{|c|}{ Empurrou-a ou deu um "tranco"? } \\
\hline $\operatorname{Sim}$ & 122 & 26,0 \\
\hline \multicolumn{3}{|l|}{ Grave $^{b}$} \\
\hline \multicolumn{3}{|c|}{ Marido/companheiro machucou-a com um soco ou objeto? } \\
\hline $\operatorname{Sim}$ & 87 & 18,5 \\
\hline \multicolumn{3}{|c|}{ Deu um chute, arrastou ou surrou? } \\
\hline $\operatorname{sim}$ & 53 & 11,2 \\
\hline \multicolumn{3}{|c|}{ Estrangulou ou queimou de propósito? } \\
\hline $\operatorname{Sim}$ & 26 & 5,5 \\
\hline \multicolumn{3}{|c|}{ Ameaçou usar ou usou arma de fogo, faca ou outro tipo de arma? } \\
\hline Sim & 56 & 11,9 \\
\hline \multicolumn{3}{|l|}{ Sexual } \\
\hline \multicolumn{3}{|c|}{ Forçou-a fisicamente a ter relações sexuais? } \\
\hline $\operatorname{Sim}$ & 53 & 11,3 \\
\hline \multicolumn{3}{|c|}{ Teve relação sexual por medo do que ele pudesse fazer? } \\
\hline Sim & 55 & 11,7 \\
\hline \multicolumn{3}{|c|}{ Forçou a prática sexual degradante? } \\
\hline $\operatorname{sim}$ & 30 & 6,4 \\
\hline
\end{tabular}

a Violência física moderada: dar tapas ou jogar algo; empurrar.

b Violência física grave: chutar, surrar, estrangular ou queimar, usar armas.

A tabela 4 apresenta a análise bivariada para a ocorrência de todos os tipos de violência praticada pelo parceiro íntimo contra a mulher. As variáveis significantes $(\mathrm{p}<0,05)$ associadas à VPPI e, portanto, que podem ser consideradas como prováveis fatores de risco para a ocorrência desse tipo de violência contra a mulher foram: psicológica (grau de instrução $\leq 8$ anos, ter problema de saúde e julgar-se violenta); física (grau de instrução $\leq 8$ anos, ter problema de saúde, sentir dor de cabeça ou enxaqueca e julgar-se violenta); sexual (idade $\leq 49$ anos, casada, grau de instrução $\leq 8$ anos, ser chefe de família, consumir bebida alcoólica, ter algum problema de saúde, julgar-se violenta). 
Tabela 4. Análise de ocorrência das violências psicológica, física e sexual, praticadas pelo parceiro íntimo, segundo variáveis estudadas

\begin{tabular}{|c|c|c|c|c|c|c|}
\hline Variáveis & \multicolumn{2}{|l|}{ Psicológica $\mathrm{Na}(\%)$} & \multicolumn{2}{|l|}{ Física Na (\%) } & $\begin{array}{r}\text { Violência } \\
\text { Sexual Na (\%) }\end{array}$ & Valor $p$ \\
\hline \multicolumn{7}{|l|}{ Idade (anos) } \\
\hline$\leq 49$ & $172(52,4)$ & 0,895 & $93(30,2)$ & 0,962 & $42(12,8)$ & 0,007 \\
\hline$>49$ & $68(53,1)$ & & $35(30,4)$ & & $29(23,2)$ & \\
\hline \multicolumn{7}{|l|}{ Estado Civil } \\
\hline Solteirab & $95(58,6)$ & 0,076 & $46(31,7)$ & 0,720 & $35(21,9)$ & 0,015 \\
\hline Casadac & $150(50,0)$ & & $85(30)$ & & $39(13,1)$ & \\
\hline \multicolumn{7}{|l|}{ Grau de instrução (anos) } \\
\hline$\leq 8$ & $153(58,2)$ & 0,007 & $83(35,2)$ & 0,014 & $57(21,8)$ & 0,000 \\
\hline$>8$ & $86(45,3)$ & & $44(24)$ & & $17(9,0)$ & \\
\hline \multicolumn{7}{|l|}{ Chefe da família } \\
\hline Parceiro/marido & $124(49,6)$ & 0,134 & $66(28,1)$ & 0,308 & $32(12,9)$ & 0,045 \\
\hline Entrevistada ou familiar & $109(56,8)$ & & $57(32,8)$ & & $38(20)$ & \\
\hline \multicolumn{7}{|c|}{ Renda familiar (em salários mínimos) } \\
\hline$\leq 3$ sal. mínimos & $204(53,8)$ & 0,157 & $109(31,1)$ & 0,369 & $60(16)$ & 0,532 \\
\hline >3 sal. mínimos & $24(43,6)$ & & $13(25)$ & & $7(12,7)$ & \\
\hline \multicolumn{7}{|l|}{ Não informado } \\
\hline \multicolumn{7}{|c|}{ Número de pessoas que residem na casa } \\
\hline$>4$ & $84(54,2)$ & 0,722 & $50(33,8)$ & 0,300 & $24(15,5)$ & 0,779 \\
\hline$\leq 4$ & $161(52,4)$ & & $81(28,9)$ & & $50(16,5)$ & \\
\hline \multicolumn{7}{|l|}{ Trabalha atualmente } \\
\hline Sim & $84(56,0)$ & 0,394 & $44(32,1)$ & 0,658 & $22(14,8)$ & 0,565 \\
\hline Não & $161(51,8)$ & & $87(30,0)$ & & $52(16,9)$ & \\
\hline \multicolumn{7}{|l|}{ Desemprego na família } \\
\hline Sim & $107(54,9)$ & 0,527 & $60(32,1)$ & 0,617 & $27(13,8)$ & 0,226 \\
\hline Não & $137(51,9)$ & & $71(29,8)$ & & $47(18,1)$ & \\
\hline \multicolumn{7}{|c|}{ Consome bebida alcoólica } \\
\hline Sim & $37(60,7)$ & 0,200 & $18(35,3)$ & 0,439 & $15(25,4)$ & 0,038 \\
\hline Não & $208(51,9)$ & & $113(30,0)$ & & $59(14,8)$ & \\
\hline \multicolumn{7}{|c|}{ Tem algum problema de saúde } \\
\hline Sim & $137(58,8)$ & 0,014 & $77(36,7)$ & 0,008 & $49(21,4)$ & 0,002 \\
\hline Não & $108(47,4)$ & & $54(24,9)$ & & $25(11)$ & \\
\hline \multicolumn{7}{|c|}{ Última consulta com um médico (meses) } \\
\hline$<6$ & $196(52,7)$ & 0,688 & $107(30,9)$ & 0,820 & $54(14,7)$ & 0,073 \\
\hline$>6$ & $49(55,1)$ & & $24(29,6)$ & & $20(22,5)$ & \\
\hline \multicolumn{7}{|c|}{ Sente dor de cabeça ou enxaqueca } \\
\hline Sim & $175(55,2)$ & 0,166 & $102(35,1)$ & 0,004 & $55(17,5)$ & 0,243 \\
\hline Não & $70(48,3)$ & & $29(21,2)$ & & $19(13,2)$ & \\
\hline \multicolumn{7}{|l|}{ Se acha violenta } \\
\hline Sim & $79(68,7)$ & 0,000 & $48(47,1)$ & 0,000 & $26(22,8)$ & 0,026 \\
\hline Não & $166(47,8)$ & & $83(25,5)$ & & $48(14,0)$ & \\
\hline
\end{tabular}

a Número de mulheres que sofreram violência moral e/ou psicológica, física e sexual.

b Solteira: representa as mulheres solteiras, divorciadas, desquitadas e viúvas.

c Casada: representa as mulheres casadas e as que vivem em união estável. 
As variáveis das análises univariadas com valor $\mathrm{p}<0,20$ nas três dimensões da VPPI pesquisadas (física, psicológica e sexual) foram incluídas no modelo multivariado de regressão logística. Assim, para análise da violência psicológica, foram incluídas as variáveis: estado civil; grau de instrução; chefe de família; renda familiar; consumir bebida alcoólica; ter algum problema de saúde; sentir dor de cabeça ou enxaqueca; e julgar-se violenta. Para análise da violência física, foram incluídas as variáveis: grau de instrução; ter algum problema de saúde; sentir dor de cabeça ou enxaqueca; e julgar-se violenta. Para análise da violência sexual, foram incluídas as variáveis: idade; grau de instrução; estado civil; ser chefe de família; consumir bebida alcoólica; ter algum problema de saúde; há quanto tempo procurou um médico; julgar-se violenta.

A tabela 5 apresenta o modelo final da análise multivariada, mostrando as variáveis associadas significativamente $(\mathrm{p}<0,05)$ à ocorrência de VPPI nas três dimensões pesquisadas. Para a ocorrência da VPPI psicológica, encontrou-se que ser casada reduz a chance $(\mathrm{OR}=0,597)$ de sofrer esse tipo de violência, enquanto julgar-se violenta $(\mathrm{OR}=2,038)$, ter baixa escolaridade $(\mathrm{OR}=3,194)$ e consumir bebida alcoólica $(\mathrm{OR}=3,669)$ aumentam as chances de ser psicologicamente violentada. Ser agredida fisicamente pelo parceiro íntimo associou-se significativamente a: baixa escolaridade (OR=1,629), sentir dor de cabeça ou enxaqueca $(\mathrm{OR}=1,761)$ e julgar-se violenta $(\mathrm{OR}=2,038)$. Quanto à ocorrência da VPPI sexual, as variáveis ser casada $(\mathrm{OR}=0,511)$ e ter idade $\geq 49$ anos $(\mathrm{OR}=0,542)$ se associaram a menor chance de violência. Ao contrário, consumir bebida alcoólica $(\mathrm{OR}=2,724)$ e ter baixa escolaridade $(\mathrm{OR}=2,797)$ mostraram-se significativamente associadas à violência sexual provocada pelo parceiro íntimo. Percebe-se que a baixa escolaridade foi a variável que permaneceu em todos os tipos de VPPI, associando-se significativamente a maior chance de ocorrência de violência psicológica, física e/ou sexual.

Tabela 5. Modelo final da regressão logística para as violências psicológica, física e sexual, relatadas pelas 470 mulheres entrevistadas em Ribeirão das Neves, Minas Gerais

\begin{tabular}{lrrr}
\hline Variáveis & OR & IC 95\% & p \\
\hline Violência Psicológica & & & \\
\hline Estado Civil - (casada) & 0,597 & $0,358 \rightarrow 0,994$ & 0,047 \\
Julga-se violenta - (sim) & 2,038 & $1,267 \rightarrow 3,277$ & 0,003 \\
$<8$ anos de escolaridade & 3,194 & $1,745 \rightarrow 5,845$ & 0,000 \\
Consome bebida alcoólica - (sim) & 3,669 & $2,182 \rightarrow 6,168$ & 0,000 \\
\hline Violência Física & & & \\
\hline$<8$ anos de escolaridade & 1,629 & $1,093 \rightarrow 2,427$ & 0,017 \\
Sente dor de cabeça e/ou enxaqueca - (sim) & 1,761 & $1,091 \rightarrow 2,841$ & 0,021 \\
Julga-se violenta - (sim) & 2,038 & $1,484 \rightarrow 2,799$ & 0,000 \\
\hline Violência Sexual & & & \\
\hline Estado Civil - (casada) & 0,511 & $0,298 \rightarrow 0,878$ & 0,015 \\
Idade $\geq 49$ anos & 0,542 & $0,298 \rightarrow 0,985$ & 0,045 \\
Desemprego na família - (sim) & 0,582 & $0,334 \rightarrow 1,015$ & 0,057 \\
Consome bebida alcoólica - (sim) & 2,724 & $1,342 \rightarrow 5,53$ & 0,006 \\
$<8$ anos de escolaridade & 2,797 & $1,462 \rightarrow 5,352$ & 0,002 \\
\hline
\end{tabular}




\section{Discussão}

Os achados referentes às características sociodemográficas das mulheres entrevistadas, como renda inferior a três salários mínimos e baixa escolaridade, condizem com as informações disponibilizadas pelo Instituto Brasileiro de Geografia e Estatística (IBGE), no Censo 2010"11, para o município de Ribeirão das Neves. De acordo com o IBGE, a prevalência da pobreza e da pobreza subjetiva é de $23,2 \%$ e $16,9 \%$, respectivamente, na população absoluta do município. No tocante à escolaridade, $49,1 \%$ das mulheres com ocupação remunerada, com 25 anos ou mais de idade, não têm instrução ou não completaram o ensino fundamental. As ocupações para trabalhadores que não possuem qualificação se sobressaem, reforçando a baixa escolaridade da população estudada.

A prevalência da violência contra a mulher provocada pelo parceiro íntimo (VPPI) encontrada neste estudo para as dimensões psicológica (42,8\%), física (26\%) e sexual (12\%) é corroborada por outros estudos nacionais que relatam que $56,4 \%$ das 2.379 mulheres entrevistadas afirmaram ter sofrido VPPI, e encontraram prevalência de VPPI em 59,8\% das 2.780 mulheres pesquisadas ${ }^{12,13}$. Em outras pesquisas com amostras semelhantes ao nosso estudo, os achados da prevalência da VPPI foram $34,5 \%, 27,5 \%$ e $28,9 \%$, respectivamente14-17. Em estudo internacional envolvendo 15.081 mulheres, encontrou-se que $49,8 \%$ das mulheres entrevistadas relataram ter sofrido algum tipo de violência provocada pelo parceiro íntimo ${ }^{17}$.

A violência psicológica no nosso estudo foi a mais prevalente entre todas as formas de violência (42,8\%), achado bastante concordante com os resultados de outros autores, que observaram que $41,4 \%$ e $42,4 \%$ das mulheres entrevistadas referiram ter sofrido VPPI psicológica ${ }^{17,18}$. Pesquisa realizada em todo o território nacional dos Estados Unidos revelou que $48,4 \%$ de todas as mulheres do país já sofreram violência psicológica provocada pelo parceiro íntimo, em algum momento de suas vidas $^{19}$. A VPPI física foi relatada por $26,0 \%$ da população desse estudo. Pesquisa realizada em vários países revelou que 10,0 a 69,0\% das mulheres na faixa etária de 15 a 49 anos sofreram algum tipo de abuso físico por seus parceiros ${ }^{\mathbf{1}}$. Alguns autores, utilizando como base o mesmo instrumento de nosso estudo, observaram que $34,5 \%$ das 501 mulheres da amostra sofreram VPPI ${ }^{13}$. Outros autores também demonstraram que a prevalência da violência física contra a mulher, provocada pelo parceiro íntimo, é alarmante, tendo sido relatada por $19,7 \%$ das mulheres pesquisadas, $31,3 \%$ e $35,6 \%$ das mulheres participantes de variados estudos ${ }^{17-19}$.

Já a VPPI sexual foi prevalente em 11,7\% das entrevistadas em nosso estudo. Os achados de outros pesquisadores foram: $9,2 \% ; 16,9 \%$; $30 \%$ das mulheres pesquisadas ${ }^{17-19}$. Em estudo multicêntrico, a OMS encontrou que entre 6,0 a 59,0\% das mulheres em todo o mundo sofreram abuso sexual cometido pelos parceiros ${ }^{8}$.

No presente estudo, investigou-se uma população dependente do serviço público de saúde e que utiliza os serviços médicos com frequência. Entretanto, quando perguntadas sobre terem quaisquer problemas de saúde, quase metade das entrevistadas negou sua existência. Problemas de saúde e dor de cabeça e/ou enxaqueca estão associados à VPPI nas três categorias em nosso estudo. Parcela expressiva referiu episódios de dor de cabeça ou enxaqueca, seguidos de relatos de dores no corpo $^{20}$. Analisando entrevistas de 13.094 mulheres da Pesquisa Nacional de Saúde na Espanha, encontrou-se que havia associação entre dores crônicas, autopercepção de saúde deficiente e sofrimento psiquíco devido à VPPI.

Percebe-se que ainda é muito difícil para as vítimas de agressão buscar ajuda levando como queixa principal a violência sofrida, seja por vergonha, medo ou por dificuldade de se expor. O que ocorre é que o atendimento no âmbito da saúde é voltado para as queixas explícitas, e essa visão está arraigada tanto nos pacientes quantos nos profissionais de saúde ${ }^{20}$.

Os achados do nosso estudo mostraram que baixo grau de instrução e baixa renda 
estão associados com a ocorrência de VPPI. Essa associação foi também encontrada em outros estudos, nos quais foi observado que baixa escolaridade era fator de risco para a ocorrência de VPPI física ${ }^{14-16}$.

O consumo de álcool pela mulher foi associado à ocorrência da VPPI nas três dimensões desse tipo de violência encontradas neste estudo, em concordância com outras publicações ${ }^{14,17,21}$. O uso de álcool e outras drogas foi associado à violência e pode ser considerado fator preditivo desse fenômeno ${ }^{\mathbf{2 1}, 22}$.

Julgar-se violenta apresentou associação significante para a ocorrência de VPPI em todas as dimensões da violência íntima. Estudos internacionais referem a associação de julgar-se violenta, entre mulheres vítimas de VPPI, e atitudes de aceitação com relação à violência ${ }^{17,22,23}$. Outros autores também descreveram essa associação entre a VPPI e o histórico familiar de violência ${ }^{14,15}$.

Nesse sentido, a análise da violência como modelo ecológico, proposto pela $\mathrm{OMS}^{\mathbf{2 4}}$, ajuda a compreender o fenômeno da violência, pois ele é o resultado da complexa interação de fatores individuais e das relações sociais, culturais e ambientais. Cada vez mais, a sociedade tem se utilizado de atos violentos para a resolução de conflitos, demonstrando uma dificuldade em usar recursos da mediação, principalmente a fala, e, a partir dela, abrir a possibilidade de negociar, argumentar, enfim, de utilizar outros recursos para além da força física para resolução dos problemas.

É fundamental que os profissionais de saúde reconheçam a violência que se estabelece no âmbito doméstico, principalmente a praticada contra a mulher, como um grave problema de saúde pública. $\mathrm{E}$, ao mesmo tempo, que fiquem atentos para o fato de que os serviços de saúde são os espaços ideais para a detecção desses casos, constituindo-se em uma importante rede de atenção à saúde da mulher em situação de risco ${ }^{25,26}$. Toda e qualquer busca de consultas em unidades da APS deve ser aproveitada para a oferta de espaços de trocas e de aprendizagem, para que as pessoas possam, de fato, participar da produção de sua saúde.

Garcia-Moreno et al. ${ }^{25}$ referem em seu estudo que os profissionais da APS não priorizam as ações de prevenção e enfrentamento da violência, apesar de reconhecerem a violência conjugal como um problema de saúde pública. Segundo esses autores, ainda existe por parte dos profissionais de saúde o receio de notificar a violência, sendo necessário discutir esse tema e implementar ações mais efetivas ${ }^{25}$. Por sua vez, a subnotificação da violência contra a mulher pode contribuir para manter a impunidade do agressor. Ainda não está claro para os profissionais de saúde que as notificações de violência são importantes instrumentos para subsidiar a necessidade de formulação de políticas para o setor ${ }^{27}$.

\section{Conclusões}

O presente estudo procurou tipificar as violências praticadas contra a mulher por seus parceiros, nas relações íntimas de afeto. Não foi analisada a ocorrência da violência sofrida pela mulher, de forma mais ampla, em algum outro momento de sua vida. Essas informações certamente enriqueceriam a discussão, mas poderão ser analisadas posteriormente. Apesar dessas limitações, os resultados deste estudo podem ser utilizados para o desenvolvimento de estratégias de identificação precoce da violência e de capacitação dos profissionais da saúde. Foi demonstrado que violências de vários tipos contra a mulher provocadas por parceiro íntimo estão muito presentes na sociedade, e com uma frequência importante entre as usuárias da APS do município de Ribeirão das Neves. Fatores como baixo grau de instrução, baixa renda e, consequentemente, dependência financeira estão diretamente associados com a ocorrência de VPPI, interferindo na saúde dessas mulheres, que, 
muitas vezes, desenvolvem sintomas físicos ou psicológicos, demandando atendimentos em unidades de saúde com muita frequência, mas sem melhoria da qualidade de vida.

A violência que se estabelece no âmbito doméstico é bastante velada. Ainda há dificuldade em expor as questões mais íntimas de afeto, levando muitas vezes a um desconhecimento da gravidade da situação e, consequentemente, a maior dificuldade de se estabelecer políticas públicas eficazes. Daí a importância de se debater esse tema de forma ampla e buscar alternativas que possam minimizar o sofrimento de um número significativo de mulheres.

\section{Referências}

1. Organização Mundial de Saúde. Natureza, magnitude e consequências da violência sexual e da violência por parceiro íntimo. In: Prevenção da Violência Sexual e da Violência pelo Parceiro Íntimo Contra a Mulher: Ação e produção de evidência. Brasília, DF: Organização Mundial da Saúde; 2012. p. 11-17.

2. Pan American Health Organization. Centers for Disease Control and Prevention. Violence Against in Latin America and the Caribbean: A comparative analysis of population-based data from 12 countries. Washington, DC: PAHO; 2012. [acesso em 2013 jun 26]. Disponível em: http://www2.paho.org/hq/dmdocuments/violence-against-women-lac.pdf.

\section{Colaboradores}

Rosa DOA contribuiu substancialmente para a concepção, o planejamento e para a análise e a interpretação dos dados, além de ter participado da aprovação da versão final do manuscrito. Ramos RCS e Gomes TMV contribuíram significativamente para a elaboração do rascunho. Melo EM contribuiu significativamente para a elaboração do rascunho e a revisão crítica do conteúdo. Melo VH contribuiu substancialmente para a concepção, o planejamento e para a análise e a interpretação dos dados, além de ter participado da aprovação da versão final do manuscrito.
3. Waiselfisz JJ. Mapa da violência, 2012. Atualização: homicídios em mulheres no Brasil. Brasília, DF: FLACSO Brasil; 2012.

4. Guedes RN, Fonseca RMGS, Egry EY. Limites e possibilidades avaliativas da estratégia saúde da família para a violência de gênero. Rev. Esc. Enfermagem USP. 2013; 47(2):304-11.

5. Schraiber LB, Barros CRS, Castilho E. A. Violência contra as mulheres por parceiros íntimos: usos de serviços de saúde. Rev. Bras. Epidemiol. 2010; 13(2):2345 . 
6. Kind L, Orsini MLP, Nepomuneno V, et al. Subnotificação e (in)visibilidade da violência contra mulheres na atenção primária à saúde. Cad. Saúde Pública. 2013; 29(9):1805-15.

7. Brasil. Lei no 10.778, de 24 de novembro de 2003. Estabelece a notificação compulsória, no território nacional, do caso de violência contra a mulher que for atendida em serviços de saúde públicos ou privados. Diário Oficial da União. 25 Nov 2003.

8. World Health Organization. Multi-Country study on women's health and domestic violence against women: summary report of initial results on prevalence, health outcomes and women's responses. Geneva: World Health Organization, 2005. [acesso em 2013 jun 26]. Disponível em: http://www.who.int/gender/ violence/who_multicountry_study/summary_report/ summary_report_English2.pdf.

9. Schraiber LB, Latorre MRDO, França JR. I, etc. Validade do instrumento WHO VAWSTUDY para estimar violência de gênero contra a mulher. Rev. Saúde Pública. 2010; 44(4):658-666.

10. Gomes TMV, Rosa DOA, Tavares R, et al. Avaliação da interface dos diferentes tipos de violência provocada pelo parceiro íntimo contra a mulher. Rev. Med. Minas Gerais. 2016; 26 (supl8):62-67

11. Instituto Brasileiro de Geografia e Estatística. Bibilioteca. [acesso em 2015 out 27]. Disponível em: http:// biblioteca.ibge.gov.br/biblioteca-catalogo?view=det alhes\&id=254598.

12. Osis MJD, Duarte GA, Fagundes A. Violência entre usuárias de unidades de saúde: prevalência, perspectiva e conduta de gestores e profissionais. Rev. Saúde Pública. 2012; 46(2):351-358.

13. Barros C, Schraiber LB, França-Júnior I. Associação entre violência por parceiro íntimo contra a mulher e infecção por HIV. Rev. Saúde Pública 2011; 45:365372.

14. Vieira EM, Perdona GSC, Santos MA. Fatores associados à violência física por parceiro íntimo em usu- árias de serviços de saúde. Rev Saúde Pública 2011; 45(4):730-737.

15. Silva MA, Falbo Neno GH, Figueiroa JN, et al. Violence against women: prevalence and associated factors in patients attending a public healthcare service in the Northeast of Brazil. Cad. Saúde Pública 2010; 26(2):254-272.

16. D’Oliveira AFPL, Schraiber LB, França-Júnior I, et al. Fatores associados à violência por parceiro íntimo em mulheres brasileiras. Rev. Saúde Pública 2009; 43(2):299-310.

17. Kouyoumdjian FG, Calzavara LM, Bondy SJ, et al. Risk factors for intimate partner violence in women in the Rakai Community Cohort Study, Uganda, from 2000 to 2009. BMC Public Health. 2013; 13:566.

18. Chimah CU, Adogu POU, Odeyemi K, et al. Comparative analysis of prevalence of intimate partner violence against women in military and civilian communities in Abuja, Nigeria. International Journal of Women's Health 2015; 7:287-295.

19. Black MC, Basile KC, Breiding MJ, et al. (2011). The National Intimate Partner and Sexual Violence Survey (NISVS): 2010 Summary Report. Atlanta, GA: National Center for Injury Prevention and Control, Centers for Disease Control and Prevention.

20. Vives-Cases C, Ruiz-Cantero MT, Aguir VE, et al. The effect of intimate partner violence and other forms of violence against women on health. Journal of Public Health. 2010; 33(1):15-21.

21. Lindner SR, Coelho EBS, Bolsoni CC, et al. Prevalência de violência física por parceiro íntimo em homens e mulheres de Florianópolis, Santa Catarina, Brasil: estudo de base populacional. Cad. Saúde Pública. 2015; 31(4):815-826.

22. Zaleski M, Pinskyii I, Laranjeira, et al. Violência entre parceiros íntimos e consumo de álcool. Rev. Saúde Pública 2010;44(1):53-59.

23. Heise LL, Aandreas K. Cross-national and multile- 
vel correlates of partner violence: an analysis of data from population-based surveys. Lancet Glob Health 2015; 3(6):332-340.

24. Organização Mundial de Saúde. Genebra: OMS; 2002. Version of the Introduction to the World Report on Violence and Health (WHO). Geneve: WHO, 2002

25. García-Moreno C, Hegarty K, D’Oliveira AFL, et al. The health-systems response to violence against women. Lancet. 2015; 385:1567-1579.

26. Gomes NP, Erdman AL. Violência conjugal na perspectiva de profissionais da "Estratégia Saúde da Fa- mília”: problema de saúde pública e a necessidade do cuidado à mulher. Rev. Latino-Am. Enfermagem. 2014; 22:1.

27. Souza CS, Costa MCO, Carvalho RC, et al. Notificação da violência infanto-juvenil em Serviços de Emergência do Sistema Único de Saúde em Feira de Santana, Bahia, Brasil. Rev. Bras. Epidemiol. 2015 mar; 18(1):80-93.

Recebido em 04/12/ 2017 Aprovado em 19/11/2018

Conflito de interesses: inexistente

Suporte financeiro: não houve 